\title{
Performing at extreme altitude: muscle cellular and subcellular adaptations
}

Accepted: 28 April 2003 / Published online: 25 July 2003

(C) Springer-Verlag 2003

\begin{abstract}
This review reports on the collaborative efforts of the Department of Physiology of the University of Geneva headed by Paolo Cerretelli, the Research Institute at the Federal School of Physical Education in Magglingen and the Department of Anatomy of the University of Bern to elucidate the functional and structural conditions for and consequences of climbing successfully at altitudes in excess of $8000 \mathrm{~m}$. Using a combination of physiological whole body measurements with biochemical, histochemical and morphometric analyses of muscle biopsy samples we were able to establish specific phenotypical alterations of muscle tissue exposed to extreme hypoxia and stress for prolonged periods of time. The decline in aerobic work capacity could be shown to be a consequence of a loss of muscle mass as well as of muscle tissue oxidative capacity whereby muscle capillarity was found to be maintained. The degradation of muscle tissue was further characterized by an increase in muscle lipofuscin. The latter is believed to be the consequence of lipid peroxidation eventually related to mitochondrial loss. Current work ensuing from our long-term collaboration suggests that Sherpas might be protected against the damaging effect of hypoxia by antioxidant mechanisms protecting their muscles under the conditions of extreme altitude.
\end{abstract}

Keywords Hypoxia - Lipofuscin - Mitochondria Morphometry $\cdot \mathrm{VO}_{2 \max }$

The present review aims at purveying the background and key insights as well as the sense of excitement that were the fruits of a collaboration with Paolo Cerretelli that lasted for over 20 years. Starting in the early 1970s the Department of Anatomy of the University of Bern and the Research Institute of the Federal School of

H. Howald · H. Hoppeler $(\bowtie)$

Department of Anatomy, University of Bern, Buehlstrasse 26, 9,3000 Bern, Switzerland

E-mail: hoppeler@ana.unibe.ch

Tel.: + 41-31-6314637

Fax: +41-31-6313807
Physical Education of Magglingen carried out a number of biopsy studies combining functional estimates of various aspects of physical performance capacity in athletes with ultrastructural measurements of muscle tissue components relating mitochondria and capillaries to endurance parameters (Hoppeler et al. 1973; Zumstein et al. 1983) and myofibrils to strength parameters (Luethi et al. 1986). The broad goal of our work at that time was to find the structural correlates to the functional differences that exercise training could induce in muscle and the whole body function of athletes. It was certainly the urge to find mechanistic explanations for physiological phenomena that led $\mathrm{Pa}$ olo Cerretelli to contact our groups in the early 1980s in order to establish a collaboration to study phenomena of muscle adaptation induced by exposure to the extreme hypoxic environment encountered by climbers during their ascents to the highest peak of the Earth. We were unaware at that time that this collaboration would grow into an extremely successful research partnership that was to last up to the present day for all involved.

\section{Mount Everest: the ultimate challenge in hypoxia}

It must have been a very exciting moment in his career as an exercise physiologist when Paolo Cerretelli was informed that on 8 May, 1978 world-famous Italian climber Reinhold Messner and his Austrian colleague Peter Habeler had reached the top of Mount Everest without making use of bottled oxygen. On 20 August, 1980 Messner repeated this extraordinary performance, successfully completing his solo ascent to the highest point on Earth "by fair means" for a second time.

As early as 1920 Alexander Mitchell Kellas, a British physiologist and geographical explorer of the Himalayas, predicted that "Mount Everest could be ascended by a man of excellent physical and mental constitution in firstrate training, without adventitious aids [supplementary oxygen] if the physical difficulties of the mountain are not too great" (for reference see West 1987). In an 
unpublished manuscript Kellas correctly estimated the barometric pressure on the summit of Mount Everest to be 251 torr $(33.5 \mathrm{kPa})$, the climbing rate in the final approach to the top to reach 300-350 ft/h (91.44-106.7 $\mathrm{m} / \mathrm{h}$ ) and maximal oxygen consumption $\left(\mathrm{VO}_{2 \max }\right)$ at that altitude to measure no more than $970 \mathrm{ml} / \mathrm{min}$, thus reducing the aerobic scope of climbers to essentially three times resting metabolism. In earlier publications he had also pointed out the importance of adequate acclimatization as a key factor to tolerate the extreme lack of oxygen at high altitude. Moreover, he was one of the first to describe mountain sickness and depreciation of muscle strength when staying at elevations higher than $20,000 \mathrm{ft}$ $(6096 \mathrm{~m})$. Last but not least he recognized the immense value of the Sherpas in expeditions to the Himalayas.

After Messner and Habeler had confirmed those early estimations by their exceptional performance, physiologists started to speculate on the aerobic capacities of these outstanding performers and came to the conclusion that their $V \mathrm{O}_{2 \max }$ should be as high as that found in world-class distance runners, i.e. $77-80 \mathrm{ml} \mathrm{O}_{2} \cdot \mathrm{kg}^{-1}$. $\min ^{-1}$ (Buskirk 1985). Speculation is definitely not the case for Paolo Cerretelli. Making use of his talent in organizing collaborative studies on an international level, he invited the two climbers to come to Switzerland, where they were submitted to extensive clinical and laboratory tests in the company of four other climbers, all of them having reached altitudes in excess of $8500 \mathrm{~m}$ without supplementary oxygen. It was certainly the first time that such a unique group of human subjects (Fig. 1) underwent such a complete set of investigations including spirometry, ventilatory control, oxyhaemoglobin saturation, echocardiography, muscle biopsy (Fig. 2), determination of aerobic and anaerobic power as well as efficiency of locomotion. Our laboratories were charged with carrying out the muscle biopsy samples, muscle fibre typing and muscle morphometry.

\section{Investigations in world-class high-altitude climbers}

A few weeks after reaching a series of three summits higher than $8000 \mathrm{~m}$ in the Himalayas, Reinhold Messner was running to exhaustion on a treadmill for the first time in his life (Oelz et al. 1986). Although his heart rate peaked at $184 \mathrm{bpm}$ and his blood lactate concentration was as high as $15.3 \mathrm{mM}\left(\right.$ (), his $\mathrm{VO}_{2 \max }$ was leveling off at a disappointing $48.8 \mathrm{ml} \cdot \mathrm{kg}^{-1} \cdot \mathrm{min}^{-1}$. Using a different exercise protocol this value was confirmed in Paolo Cerretelli's laboratory on the next day. The $\mathrm{VO}_{2 \max }$ of Peter Habeler reached $65.9 \mathrm{ml} \cdot \mathrm{kg}^{-1} \cdot \mathrm{min}^{-1}$ and the values for the three other climbers were found to lie between these two extremes, all of them within the range determined in our laboratories for a samples of sedentary male subjects (Fig. 3), but far away from $\mathrm{VO}_{2 \max }$ levels of $80-85 \mathrm{ml} \cdot \mathrm{kg}^{-1} \cdot \mathrm{min}^{-1}$ regularly measured in top-class endurance athletes.

Histochemistry revealed $67.0 \%$ of fatigue-resistant type I fibres for Reinhold Messner (Fig. 2) and an

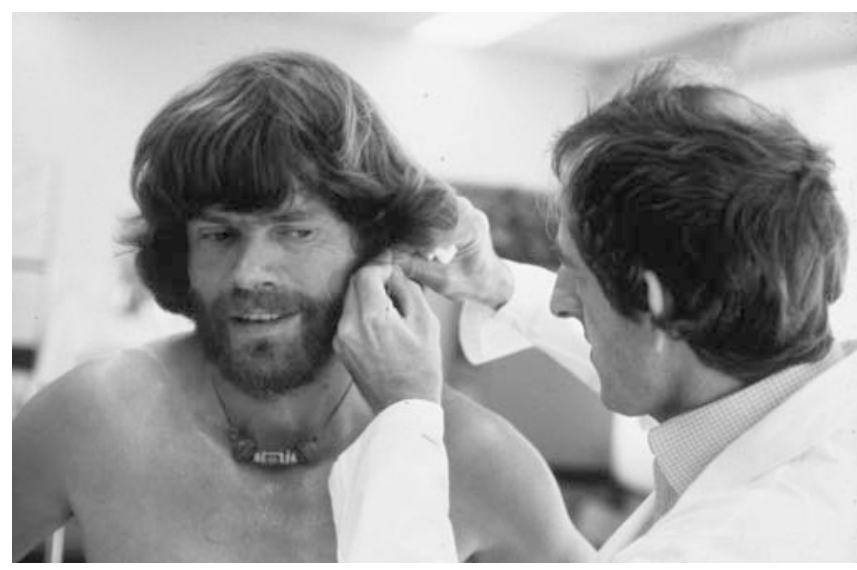

Fig. 1 Reinhold Messner tested in the exercise physiology laboratory at Magglingen, Switzerland

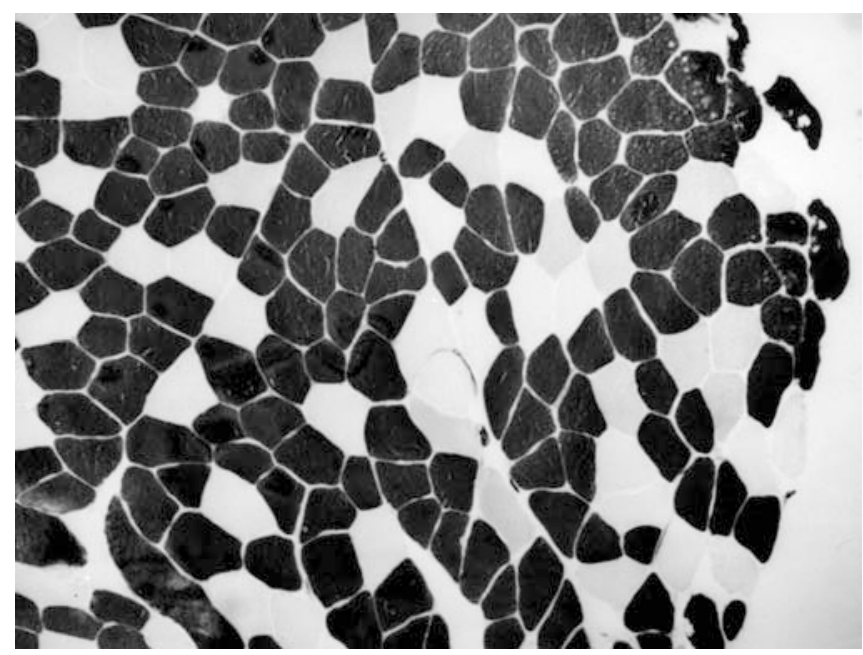

Fig. 2 Transversal section of Reinhold Messner's M. vastus lateralis. ATPase staining at $\mathrm{pH} 4.5$; type I fibres are dark, type $\mathrm{IIa}$ and $\mathrm{IIb} / \mathrm{x}$ fibers are bright

average of $70.2 \%$ for all the five climbers investigated (Oelz et al. 1986). These values are somewhat higher than those determined in sedentary male subjects, but well below those found in elite athletes involved in endurance events.

The local aerobic capacity of $\mathrm{M}$. vastus lateralis of the five climbers estimated from the volume density of mitochondria was not different from the pattern found in sedentary subjects (Fig. 3), confirming the strong correlation between $V \mathrm{VO}_{2 \max }$ and the percentage of mitochondria per muscle fibre volume which we had published previously (Hoppeler et al. 1973). Again, topclass athletes involved in endurance events would reach values in excess of $10 \%$ of fibre volume for this particular variable (Hoppeler 1986).

Capillarization of muscle fibres expressed as fibre area perfused by one single capillary was also found to lie in the normal range for untrained male subjects (Fig. 3), indicating that our climbers did not have an 


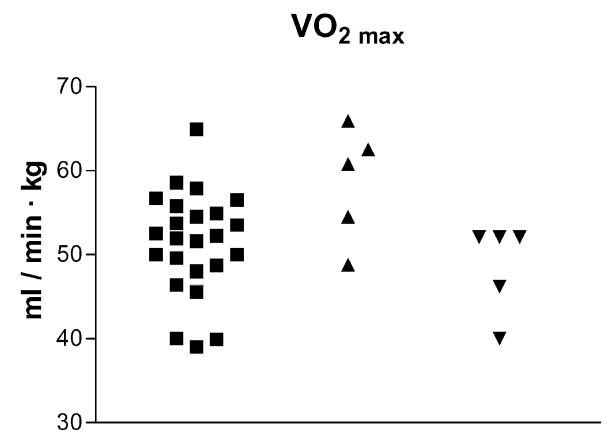

Mitochondria

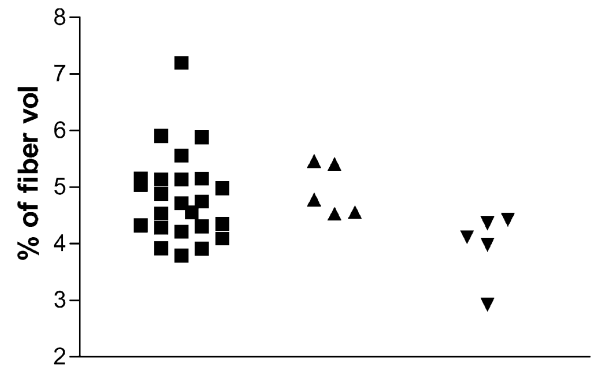

$A_{N}(f, c)$

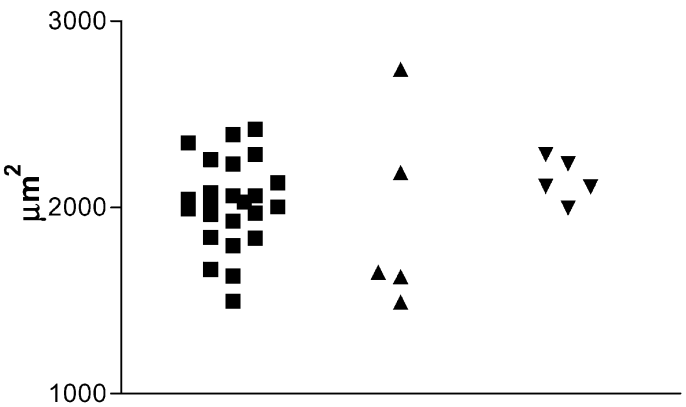

Fig. $3 \mathrm{VO}_{2 \max }$, volume density of mitochondria and muscle fibre area perfused by one capillary $\left[A_{\mathrm{N}}(\mathrm{f}, \mathrm{c})\right]$ of sedentary Caucasian subjects $(\boldsymbol{\square})$, world-class high-altitude climbers $(\boldsymbol{\Delta})$ and Himalayan Sherpas $(\boldsymbol{\nabla})$

advantage with respect to the final step of oxygen transport to the muscle fibres.

\section{Special features in Himalayan Sherpas}

Sherpas have a reputation in the history of climbing in the Himalayas because of their legendary endurance and resistance toward high-altitude stress. Thanks to Paolo Cerretelli's good relations with the authorities in Nepal it was possible to recruit five Sherpas aged 24-32 years to volunteer for $\mathrm{VO}_{2 \max }$ testing and what turned out to be much more of a problem for muscle biopsy samples as well (Kayser et al. 1991). The maximum altitudes ever reached by these five subjects ranged from 5400 to 7790 m. In Fig. 3 data for their $V \mathrm{O}_{2 \max }$, volume density of mitochondria and area of muscle tissue perfused by one single capillary are compared to the values observed in sedentary Caucasian male subjects and in the group of world-class high-altitude climbers described above. According to these data Sherpas are characterized by relatively low values for both $\mathrm{VO}_{2 \max }$ and mitochondrial volume density, whereas capillarization was found to lie in the median range of the two other groups investigated. Interestingly, the slope of the regression line for $\mathrm{VO}_{2 \max }$ versus mitochondrial volume density is similar for untrained lowlanders and the Sherpas (data not shown), but it has a significantly lower intercept (Kayser et al. 1991). Therefore, the Sherpas reach greater specific $V \mathrm{O}_{2 \max }$ levels with lower mitochondrial volume densities compared to sedentary people living at low altitudes. Since the cross-sectional area of their muscle fibres was significantly smaller than that observed in Caucasian climbers ready for an expedition to either Lhotse or Mount Everest (Hoppeler et al. 1990, see below) tissue conductance for oxygen was found to be better in the Sherpas due to a shorter diffusion path, which could be interpreted as an adaptation to chronic hypoxia (Kayser et al. 1991).

Summarizing our collaborative data it can be concluded that except for Himalayan Sherpas, climbers able to reach extreme altitudes are not necessarily different from sedentary subjects as far as indicators of general and local aerobic capacity are concerned. As stated in our publication, their success is the result of an optimal functional balance, unusual skill, strong motivation and exceptional drive (Oelz et al. 1986). Further evidence for this statement comes from the fact that 50 years after the first successful ascent to the top of Mount Everest a total of more than 1200 climbers have reached the summit, including 86 individuals who have repeated the extraordinary performance of Reinhold Messner and Peter Habeler abstaining from the use of bottled oxygen (Oelz and Boesch 2003).

\section{Effects of staying at high altitude}

Our close collaboration with Paolo Cerretelli continued when we got the chance to monitor the members of two Swiss expeditions to Lhotse Shar $(8398 \mathrm{~m})$ and Mount Everest $(8848 \mathrm{~m})$. The results of an impressive number of multidisciplinary studies have been published in a supplement issue of the International Journal of Sports Medicine entitled "Muscular Exercise at High Altitude", which was edited by Paolo Cerretelli and Guido Ferretti.

The most important changes with respect to muscle structure and function observed in the participants of the 1986 expedition to Mount Everest are summarized in Fig. 4. The seven climbers involved in that particular study failed to reach the summit because of bad weather conditions, but all of them had spent 10 weeks in a base camp at $5350 \mathrm{~m}$ and were repeatedly exposed to altitudes in excess of $8000 \mathrm{~m}$. As a consequence of enhanced catabolism the prolonged exposure to hypoxia led to a statistically significant loss in body mass, thigh 

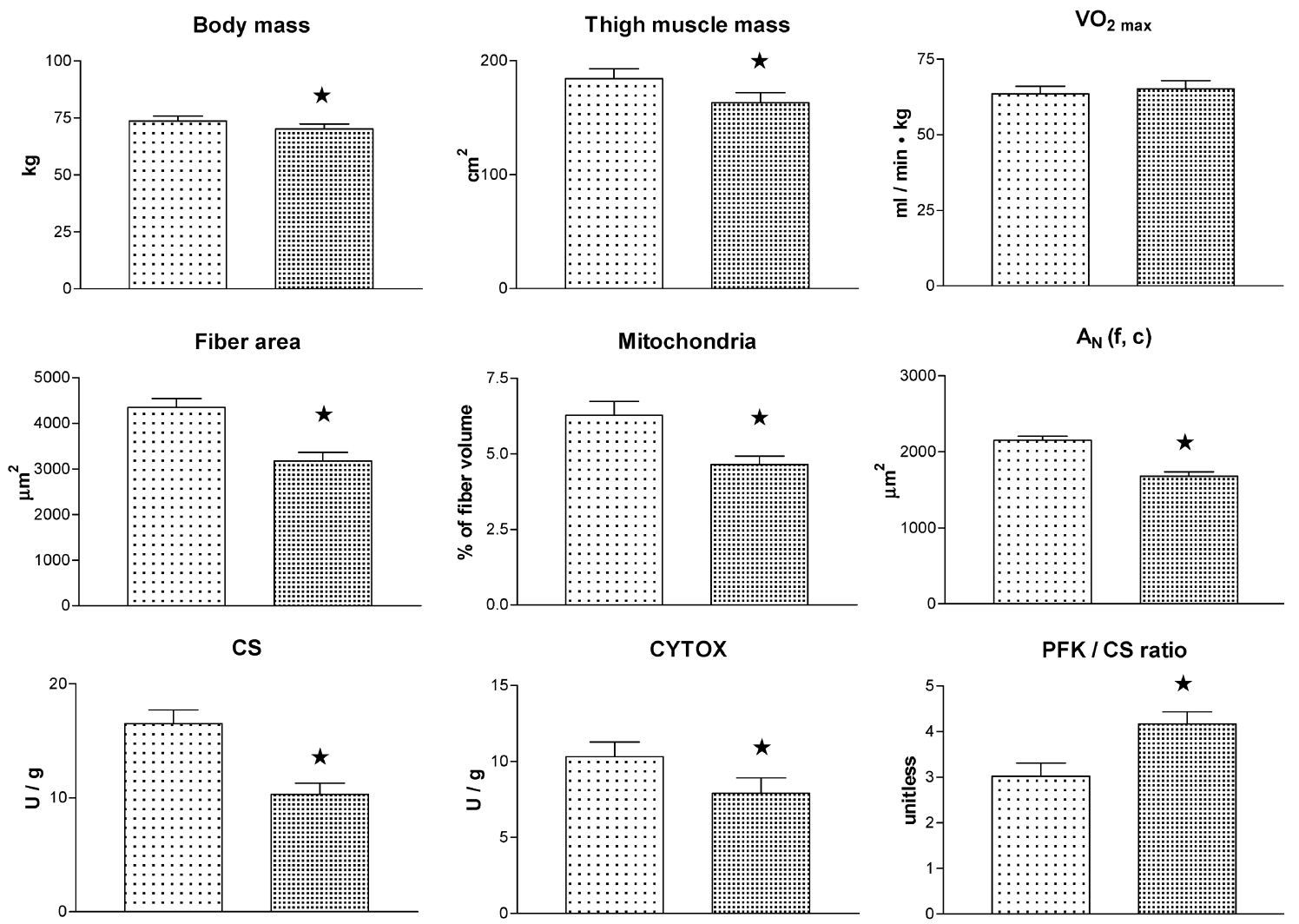

Fig. 4 Changes in body mass, thigh muscle mass determined by computer tomography, $\mathrm{VO}_{2 \max }$, muscle fibre area, volume density of mitochondria, muscle fibre area perfused by one capillary $\left[A_{\mathrm{N}}(\mathrm{f}\right.$, c)], and muscle enzyme activities (CS citrate synthase, $C Y T O X$ cytochrome c oxidase, $P F K$ phosphofructokinase) in members of an expedition to Mt. Everest. Bright columns, before departure to the Himalayas; dark columns, after returning to Switzerland

muscle mass, muscle fibre area and volume density of muscle mitochondria (Hoppeler et al. 1990). The decrease in cross-sectional muscle fibre area was combined with an increase in capillary density, leading to a significant reduction of muscle fibre volume supplied by one capillary; $A_{\mathrm{N}}$ (f, c), (Fig. 4), or in other terms to a situation of an unchanged capillary system supplying a smaller muscle oxidative capacity. On the functional level the decrement in mitochondrial volume density was confirmed by statistically significant decreases of enzyme activities responsible for the aerobic-oxidative metabolism (e.g. citrate synthase, CS, and cytochrome c oxidase, CYTOX; Fig. 4). Since this decrease was combined with an increase of enzyme activities involved in anaerobic glycolysis [the ratio of phosphofructokinase (PFK) to CS, Fig. 4] it was concluded that prolonged exposure to hypoxia together with strenuous exercise at high altitude induces an aerobic to anaerobic shift of muscle energy metabolism (Howald et al. 1990).

Our finding of a decrease of muscle oxidative capacity with long-term exposure to hypoxia was completely against the dogma of the time. It was generally assumed at that time that subjects exposed to hypoxia would respond to that challenge by increasing muscle tissue oxidative capacity. This was thought to be a mechanism maintaining muscle functionality in the face of a declining oxygen partial pressure (Hochachka et al. 1982). We presented our results for the first time 1988 at the International Symposium on Mountain Medicine in Davos, Switzerland. We knew that an American research group headed by John Sutton and John West had just finished an experiment consisting in a simulated ascent to Mount Everest in a pressure chamber and would also report on muscle biopsy samples. It was one of those great personal experiences in science when we realized that our competitors using a different approach ended up with exactly the same result: hypoxia was found to have a negative effect on muscle fibre size and tissue oxidative capacity also in the group of subjects using the pressure chamber simulation to the top of the world (MacDougall et al. 1991).

In the study of the two Swiss mountaineering expeditions we observed another aspect possibly related to the muscle fibre catabolism induced by prolonged exposure to hypoxia and physical stress. The ultrastructural studies showed evidence of accumulations of lipofuscin particles in the subsarcolemmal area (Fig. 5; Hoppeler et al. 1990).

\section{The future}

Over the last 15 years physiology has veered towards integrating the tools of molecular biology into the research agenda. This process has not been without 


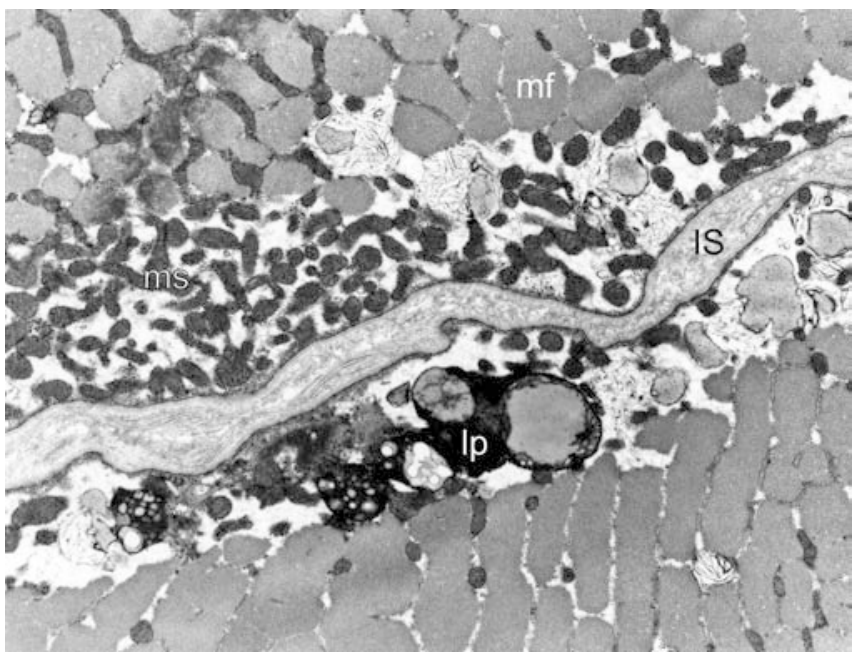

Fig. 5 Lipofuscin accumulations $(l p)$ in subsarcolemmal location of a muscle fiber ( $I S$ interstitial space, $m f$ myofibrils, $m s$ subsarcolemmal mitochondria)

stress for many of the "classical" integrative physiologists. It speaks for Paolo Cerretelli that, after initial hesitations, he has been able to embrace the new technology. Molecular tools have become increasingly accessible and we currently find a growing number of extremely well trained young molecular scientists eager to use their skills in physiological settings. It has therefore become an important issue to incorporate the new research options into the context of integrative physiology in particular into human integrative physiology. The enormous breadth of understanding and experience of "weathered" exercise physiologists such as Paolo Cerretelli has become invaluable in designing experiments aiming at elucidating the mechanisms underlying the functional and structural changes observed after high-altitude exposure. Our own research efforts have also shifted from quantitative structural description of muscle plasticity towards the study of the molecular phenomena involved in this process (see Hoppeler et al. 2003). As it turns out, a key player involved in skeletal muscle plasticity, and therefore importantly responsible for functional changes, is hypoxia. Tissue hypoxia has been shown to be responsible for the activation of a transcription factor, a master gene called hypoxia inducible factor 1 (HIF-1), leading to a suite of gene activations thus initiating adaptation to hypoxic conditions (Semenza 2000). Our findings obtained from functional and structural analyses of subjects participating in mountaineering expeditions as well as of Sherpas have thus received renewed attention and appear in a new light. We realized the immense value of the frozen biopsy material left untouched in liquid nitrogen sometimes for close to two decades. Together with Paolo Cerretelli we have now embarked on a series of new experiments in which the force of the new genomic and proteomic techniques are brought to bear on muscle biopsy material from subjects previously characterized exhaustively with classical physiological and structural techniques. Among the interesting aspects that are emerging from this new collaboration is that Sherpas might be protected from the damaging effects of longterm hypoxia exposure structurally evidenced in climbers by lipofuscin accumulations, by having adaptations of their antioxidant mechanisms in skeletal muscle tissue.

In conclusion, we look back at over 20 years of fruitful collaboration with Paolo Cerretelli, fuelled by our common interests and complementary expertise, and above all by Paolo's infecting appetite for discovery.

\section{References}

Buskirk ER (1985) Observations of extraordinary performances in an extreme environment and in training environment. In: Clarke DH, Eckert ME (eds) Limits of human performance. American Academy of Physical Education Papers No. 18. Human Kinetics, Champaign, Ill., pp 10-18

Hochachka PW, Stanley C, Merkt J, Sumar-Kalinowski J (1982) Metabolic meaning of elevated levels of oxidative enzymes in high altitude adapted animals: an interpretive hypothesis. Respir Physiol 52:303-313

Hoppeler H (1986) Exercise-induced ultrastructural changes in skeletal muscle. Int J Sport Med 7:187-204

Hoppeler H, Luethi P, Claassen H, Weibel ER, Howald H (1973) The ultrastructure of the normal human skeletal muscle; a morphometric analysis of untrained men, women, and welltrained orienteers. Pflugers Arch 344:217-232

Hoppeler H, Kleinert E, Schlegel C, Claassen H, Howald H, Kayar SR, Cerretelli P (1990) Morphological adaptations of human skeletal muscle to chronic hypoxia. Int J Sports Med 11 [Suppl. 1]:S3-S9

Hoppeler H, Vogt M, Weibel ER, Flück M (2003) Response of skeletal muscle mitochondria to hypoxia. Exp Physiol 88 (Pt.1):109-119

Howald H, Pette D, Simoneau JA, Uber A, Hoppeler H, Cerretelli P (1990) Effects of chronic hypoxia on muscle enzyme activities. Int J Sports Med 11 [Suppl. 1]:S10-S14

Kayser B, Hoppeler H, Claassen H, Cerretelli P (1991) Muscle structure and performance capacity of Himalayan sherpas. J Appl Physiol 70:1938-1942

Luethi JM, Howald H, Classen H, Roesler K, Vock P, Hoppeler H (1986) Structural changes in skeletal muscle tissue with heavyresistance exercise. Int J Sports Med 7:123-127

MacDougall JD, Green HJ, Sutton JR, Coates G, Cymerman A, Young P, Houston CS (1991) Operation Everest II: structural adaptations in skeletal muscle in response to extreme simulated altitude. Acta Physiol Scand 142:421-427

Oelz O, Boesch R (2003) Die Trophäe: Von Bergführern gecoacht, von Sherpas gestossen und gezogen - 50 Jahre nach der Erstbesteigung erobert die Spassgesellschaft den Mount Everest. FACTS 2/2003:38-49

Oelz O, Howald H, di Prampero PE, Hoppeler H, Claassen H, Jenni R, Buehlmann A, Ferretti G, Brueckner JC, Veicsteinas A, Gussoni M, Cerretelli P (1986) Physiological profile of world-class high-altitude climbers. J Appl Physiol 60:1734-1742

Semenza GL (2000) HIF-1: mediator of physiological and pathophysiological responses to hypoxia. J Appl Physiol 88(4):14741480

West JB (1987) Alexander M. Kellas and the physiological challenge of Mt. Everest. J Appl Physiol 63:3-11

Zumstein A, Mathieu O, Howald H, Hoppeler H (1983) Morphometric analysis of the capillary supply in skeletal muscles of trained and untrained subjects - its limitations in muscle biopsies. Pflugers Arch 397:277-283 